\title{
Construcción del imaginario revolucionario de jóvenes pincoyanos y la lucha armada en el Chile de los años ochenta
}

\author{
Jorge Molina Jara ${ }^{1}$ \\ Nicolás Molina Vera ${ }^{2}$ \\ Recibido: 10 de septiembre de 2014 - Aceptado: 15 de octubre de 2014
}

\begin{abstract}
Resumen
En este texto se indaga la participación de jóvenes de la población La Pincoya en la lucha armada desarrollada desde el Frente Patriótico Manuel Rodríguez en los años ochenta, analizando cómo estos jóvenes construyeron un imaginario revolucionario, que los llevó a involucrarse en esta organización militar de izquierda desarrollando diversas acciones armadas para intentar derrocar al régimen. Al respecto, se afirma como hipótesis que en el escenario de amplias protestas sociales contra la dictadura, numerosos jóvenes de la población La Pincoya acogen el llamado del Partido Comunista de agudizar las formas de lucha, involucrándose en las recientemente creadas Unidades de Combate del FPMR. Este grupo armado se nutrió principalmente de miembros jóvenes de familias comunistas, quienes construyeron un imaginario revolucionario que los impulsó a participar en emblemáticas acciones que tenían como propósito derrocar a Pinochet.
\end{abstract}

Palabras clave:Población La Pincoya, Frente Patriótico Manuel Rodríguez, Dictadura militar, lucha armada.

\section{Creation of the revolutionary imaginary of pincoyanos youth and the armed struggle in Chile of the eighties}

\begin{abstract}
This text analyzes the participation of La Pincoya settlement young people in the armed struggle developed by Frente Patriótico Manuel Rodríguez in the eighties and how these young people created a revolutionary imaginary which led them to engage in this left wind military organization developing various
\end{abstract}

Chileno. Profesor y Magíster en Historia, académico de la Universidad Católica Silva Henríquez. E-mail: jmolinaj@ucsh.cl

2 Chileno. Cientista Político, Universidad Academia de Humanismo Cristiano. E-mail: nicomoliver@gmail.com 
armed actions trying to overthrow the regime. The hypotheses is that, in an environment of broad social protests against the dictatorship, many young people from La Pincoya responded to the call of the Communist party for sharpening the struggle and engaged in the newly created Combat Units of the FPMR. This armed group was mainly fed by young members of communist families, who built a revolutionary imaginary that prompted them to engage in symbolic actions intended to overthrow Pinochet.

Keywords: La Pincoya settlement, Frente Patriótico Manuel Rodríguez, military dictatorship, armed struggle.

\title{
Construção do imaginário revolucionário dos jovens pincoyanos e a luta Armada no Chile durante os anos oitenta
}

\begin{abstract}
Resumo
Neste texto indaga-se a participação de jovens na população La Pincoya na luta armada desenvolvida a partir do Frente Patriótico Manuel Rodríguez nos anos oitenta, para se analisar como esses jovens construíram um imaginário revolucionário, que os levou a envolver-se nesta organização militar esquerdista desenvolvendo várias ações armadas para tentar derrubar o regime. Nesse sentido, afirma-se como hipótese que no cenário de amplos protestos sociais contra a ditadura, muitos jovens da população La Pincoya acolhem 0 chamado do Partido Comunista em incrementar as formas de luta, se envolvendo nas recém-criadas Unidades de Combate do FPMR. Este grupo armado conformou-se principalmente de jovens membros de famílias comunistas, construindo um imaginário revolucionário que impulsionou a participação em ações emblemáticas que tinham por objeto derrubar a Pinochet.
\end{abstract}

Palavras-chave: população La Pincoya, Frente Patriótico Manuel Rodriguez, Ditadura militar, luta armada.

A principios de los años ochenta, Chile comenzó a experimentar los efectos del receso económico mundial, a través de la paralización de la industria y el aumento explosivo del desempleo. Esta crisis y la cesantía, facilitaron a juicio de Tomás Moulian "el despertar de energías sociales dormidas" (1997: 277) de diversos sectores sociales, empezando a perder el temor tras estar enmudecidos por casi una década, expresaron su descontento en contra de la dictadura cívico-militar en el poder.

El movimiento que se generó a principios de los ochenta fue bastante diverso y masivo en sus expresiones, destacando el de los pobladores, especialmente protagonizado por jóvenes, quienes participaron activamente en las jornadas de protesta que se desarrollaron desde 1983. Al respecto, tanto la sociología como la historiografía han sido bastante fértiles, estudiando profusamente estas manifestaciones, mas no la lucha armada que se da en y desde las poblaciones contra el régimen y la previa construcción de un imaginario revolucionario que funcionó como motor de sus acciones. 
En este contexto, nos proponemos indagar cómo numerosos jóvenes de la población La Pincoya participan y construyen un imaginario revolucionario que los llevó a desarrollar diversas "acciones" armadas para intentar derrocar a la dictadura. Los jóvenes chilenos de los años ochenta, a partir de su experiencia familiar y social en un contexto de crisis, mostraron diferentes opiniones a la hora de evaluar el régimen: hubo sectores minoritarios que apoyaron fielmente al gobierno, sin embargo, la mayoría se debatió entre la despolitización y anomia (Valenzuela, 1984) y el compromiso en la lucha contra la dictadura. Estos últimos, luego de perder el miedo que años atrás los había inmovilizado, trazaron en su imaginario el camino de oposición al régimen, el cual se expresó de diversas formas, incluyendo la vía armada.

Enfocar la investigación desde la construcción de un imaginario en la lucha armada, implica necesariamente asumir que de forma anterior y entrelazada se fue incubando en los jóvenes protagonistas, en su lenguaje simbólico, algo que no existía, pero que a partir de su enunciación comienza a tomar vida propia y que sólo posteriormente pudo ser racionalizado (Castoriadis, 1984: 581). El imaginario, siguiendo a Castoriadis, alude al conjunto de significaciones colectivas, lo imaginario es capacidad imaginante: invención o creación incesante de formas, figuras, imágenes, relaciones posibles y sentidos (Castoriadis, 1994 y 2007); lo que Bernardo Subercaseaux denomina representaciones, que se constituyen tanto en la esfera de la ideología, como también de la cultura y de las mentalidades (2009: 231).

Esta forma subjetiva de significación/representación colectiva de la realidad que constituye el imaginario, se expresa en un lenguaje nutrido simbólicamente de aspectos ideológicos utópicos en los jóvenes que luchan contra la dictadura. ${ }^{3}$

El imaginario que construyen estos pobladores pincoyanos de un Chile sin dictadura y la utopía de un país socialista, solo se podría materializar a través del levantamiento popular de las masas, expresado en un proceso revolucionario de toma del poder. La revolución entendida como "tentativa acompañada del uso de la violencia de derribar a las autoridades políticas existentes y de sustituirlas con el fin de efectuar profundos cambios en las relaciones políticas, en el ordenamiento jurídico-constitucional y en la esfera socioeconómica" (Bobbio, 1984: 1458) era el camino necesario y aparece presente en el lenguaje, la literatura, los discursos, las alegorías y los símbolos de los jóvenes pobladores. La revolución por lo tanto no es un mero retornar

Desde la definición de Norberto Bobbio se indica que utopía estaría concebida como un proyecto de modificación radical de un determinado orden social, incluidos valores, instituciones o formas de la distribución de la riqueza. Donde el individuo o grupo social que lanza una propuesta de este género asume -explícita o implícitamente- que el orden social propuesto es en distintos aspectos "mejor" que el existente y, por lo tanto, digno de realizarse concretamente (Bobbio, 1984: 1661) 
a lo justo, sino que encierra la promesa y la posibilidad de construcción de un futuro mejor (Gallardo, 1997-1998: 116).

La población La Pincoya, ubicada en la zona norte de la ciudad de Santiago, nació de la toma de terrenos de los sin casa de Conchalí hacia fines de los años 60, recibiendo desde su origen una fuerte influencia de vecinos militantes comunistas, configurando una identidad y un alto grado de filiación con partidos y movimientos de izquierda. Fruto de esta identificación política y al igual que en muchas poblaciones de Santiago, tras el Golpe de Estado sus habitantes fueron víctimas de violentas intervenciones por parte de las fuerzas armadas, las cuales tenían como propósito buscar a los principales simpatizantes del depuesto gobierno y reprimir cualquier intento de sublevación. Ante esto, los pobladores fueron construyendo un imaginario que los impulsó primero tímidamente, pero luego de forma masiva y escalonada, a desarrollar distintas acciones de protesta contra la dictadura, llegando en los años ochenta a violentos enfrentamientos con la policía.

Al respecto planteamos como hipótesis que en el escenario de amplias protestas sociales contra el régimen, numerosos jóvenes de la población acogieron el llamado del Partido Comunista de agudizar las formas de lucha, involucrándose en las recientemente creadas Unidades de Combate del FPMR. Este grupo armado se nutrió principalmente de miembros jóvenes de familias comunistas, quienes construyeron un imaginario revolucionario que los impulsó a participar en emblemáticas acciones que tenían como propósito derrocar a la dictadura.

Esta investigación, como todas las desarrolladas en historia, se nutre de distintas sub-disciplinas de la historia, como lo son la historia local, ya que centra su investigación en la población La Pincoya, la historia oral, ya que recoge el relato y la memoria de quienes fueron protagonistas de los acontecimientos, y la historia política, porque analiza las tensiones y efectos que generaban las irrupciones del Frente en la lucha por recuperar la democracia. Para analizar el problema de estudio utilizaremos fuentes documentales, entrevistas y bibliografía existente sobre el tema.

\section{Antecedentes de contexto}

Tras la instalación de la Junta Militar en el poder luego del Golpe de Estado, se comienza a llevar adelante una serie de acciones destinadas a desarticular por medio de la represión, a los sectores sociales y políticos que fueron el soporte del gobierno cesado. Una clara característica que se evidenció desde el comienzo fue el antimarxismo que identificó a la cúpula militar, expresado en bandos que definían sus propias medidas como misiones liberalizadoras:

"Las Fuerzas Armadas y el cuerpo de Carabineros de Chile están unidos, para iniciar la histórica y responsable misión de luchar por la liberación de 
la patria del yugo marxista y la restauración del orden y de la institucionalidad" (Segundo Bando, Junta de Gobierno, 11 de septiembre de 1973).

A partir de esta declaración se desplegaron operaciones represivas las que fueron justificadas utilizando la tesis de la guerra interna. Dicha tesis sostenía que los partidos y grupos de izquierda querían fragmentar internamente a las naciones por medio del principio marxista de la lucha de clases, lo que ponía en riesgo la unidad nacional. Luis Corvalán Márquez sostiene: "en ese escenario, había que combatir en la lógica de la doctrina de seguridad nacional, al llamado enemigo interno, correspondiente a los sectores de izquierda" (Corvalán, 2001: 284). Por su parte la historiadora Verónica Valdivia indica que en Chile, la izquierda no significó una amenaza militar ni antes ni durante el gobierno de la Unidad Popular: "si bien en Chile la izquierda radicalizó su discurso y apoyó acciones de violencia no armada -tomas de terrenos urbanos y rurales, huelgas ilegales, etc.-, estas no revestían una amenaza militar, ni tenían una capacidad de fuego real" (Valdivia, 2010: 169). Más allá de no ser la izquierda una amenaza militar real, el contexto internacional de guerra fría en el que se produce el Golpe de Estado, junto al establecimiento interno de la tesis de seguridad nacional, llevó a las fuerzas armadas a focalizar la represión hacia sectores políticos y sociales de izquierda que fueron la base del depuesto gobierno, estableciendo en el discurso oficial, que la acción que llevaban adelante los organismos del Estado desde el 11 de septiembre, era una acción liberalizadora.

Tras el Golpe, la actividad política es suprimida, los partidos políticos son prohibidos, el Congreso Nacional fue cerrado, y los derechos políticos fueron cesados; muchos medios de comunicación fueron clausurados y los que permanecieron fueron en su mayoría intervenidos por los militares. Dirigentes políticos y sociales identificados con el gobierno depuesto tuvieron que huir del país, miles fueron detenidos, torturados o engrosan actualmente la lista de asesinados o desaparecidos por la dictadura. De forma paralela, se fueron implementando políticas neoliberales en la economía, las que contaron con el apoyo de un sector de la sociedad civil, ligado a la derecha política ${ }^{4}$ de aquel entonces y a sectores democratacristianos conservadores.

\section{Respuestas a la dictadura}

Con la prohibición de actuar y el exilio de muchos de sus militantes, los partidos políticos iniciaron una reflexión en torno al grado de responsabilidad que tuvieron en el Golpe, discusión que traería un viraje ideológico en varios de estos partidos, evidenciado a partir de las primeras jornadas de protesta.

En el libro Los civiles de Pinochet. La derecha en el régimen militar chileno, 1983-1990, publicado recientemente, Pablo Rubio examina las relaciones que establecieron personalidades y organizaciones políticas de la derecha chilena con la figura y el régimen de Pinochet. 
Las primeras protestas masivas de 1983 se dan en un contexto de crisis, con un descontento en alza por los altos índices de cesantía que impactaban con más crudeza a los sectores más pobres de la sociedad chilena. Los partidos de oposición comienzan a rearticularse de manera clandestina bajo dos coaliciones políticas: una liderada por la Democracia Cristiana y sectores socialdemócratas, configurándose la Alianza Democrática, y otra formada por el Partido Comunista, el MIR y otros sectores de izquierda, denominado Movimiento Democrático Popular (MDP). Ambos conglomerados se distinguen por la visión estratégica en torno a cómo derrotar a la dictadura: la Alianza Democrática desde un comienzo apeló a una salida pacífica vía transición política, a su vez el MDP llamaba al levantamiento popular contra la dictadura, lo que incluía la lucha armada.

\section{La Lucha Armada}

En 1980 Pinochet y sus asesores estaban empeñados en institucionalizar los cambios que venían desarrollando; para ello el cambio de la Constitución se presentó como la tarea fundamental, ya que una nueva Carta aprobada por medio de un plebiscito, permitiría a Pinochet "legitimar su gobierno" (Angell, 2005: 10). La oposición se declaró contraria a la ejecución de esta nueva institucionalidad, denunciando al plebiscito como un fraude y señalando la ilegitimidad de la nueva Constitución.

Dentro de los sectores que manifestaron su oposición a esta nueva Carta estuvo el Partido Comunista, quien en el proceso de aprobación de la nueva Constitución muestra un cambio en su estrategia para enfrentar a Pinochet. Esta nueva estrategia se venía gestando desde mediados de los años 70, luego de un arduo debate interno dado entre la vieja guardia liderada por Luís Corvalán y Volodia Teitelboim, ambos exiliados en la Unión Soviética, y la liderada por Gladys Marín más otros cuadros políticos de la dirección interior (Álvarez, 2009 y 2011). La dirección del PC centró su análisis en el hecho de no haber poseído una fuerza militar propia y en la necesidad urgente de llenar ese "vacío histórico", atendiendo a la situación apremiante de sus militantes. El debate estuvo condicionado por las vivencias a las que se ven enfrentados los cuadros intermedios del partido, quienes estando en el país deben asumir labores de dirección central en clandestinidad, enfrentándose a una fuerte represión por parte de la DINA, la cual logró capturar y hacer desaparecer a dos direcciones completas del Partido Comunista. Estos acontecimientos llevaron a muchos militantes de base a radicalizar sus posturas, masificándose dentro de las huestes la posición de enfrentar el "vacío histórico" y respaldar dentro de la estructura, al sector que pretendía el levantamiento popular y la lucha armada. Con ello se asumía que la violencia que ejercía el régimen debía ser enfrentada de igual modo, es decir, con violencia, siguiendo la línea de movimientos 
revolucionarios comunistas de Centro América. El PC, demostrando su tradición legalista, justificó su nueva política en el principio político-jurídico del derecho a la rebelión de los pueblos contra un tirano.

Con la aprobación de la Constitución de 1980, se vislumbra la posibilidad de que Pinochet se perpetúe en el poder, por ello y tras los debates internos, la dirección del PC decide extremar sus formas de lucha contra la dictadura, incluyendo la violencia aguda. El Secretario General del PC Luís Corvalán, da a conocer la nueva política indicando: "Es el fascismo el que crea una situación frente a la cual el pueblo no tendrá otro camino que recurrir a todos los medios a su alcance, a todas las formas de combate que lo ayuden, incluso de violencia aguda, para defender su derecho al pan, a la libertad y a la vida." (Corvalán, 1980: 16).

Con este cambio en la táctica política del partido (Corvalán Marquez, 2001), la dirigencia "se abocó en el diseño político y orgánico para implementar en terreno la política militar del partido" (Álvarez, 2011: 194), comenzando a congregar a los cuadros que habían tenido preparación militar en países socialistas, muchos de los cuales tenían experiencia guerrillera en Centro América. De esta manera, el PC establece su Política de Rebelión Popular de Masas (PRPM), creando el FPMR, organización militar con rasgos de guerrilla urbana, para acabar con la dictadura.

La idea fundamental del PC era no transformar al partido en una estructura netamente militar, sino que agudizar y extender todas las formas de lucha, "bajo esta concepción, lo militar no debía actuar por fuera de la acción de masas, sino con ella, para potenciarla y ampararla [...], lo principal era la movilización social, y no lo militar" (Martínez, 2008). Para Rolando Álvarez, el PC buscó con la creación del Frente y con la Política de Rebelión Popular de Masas "el desarrollo de un movimiento de masas multifacético y multiforme que desemboque en una rebelión del pueblo, que pase por el paro nacional de las actividades (...) combinar las huelgas y otras manifestaciones de masas con otras formas de lucha, violencia aguda, comprendidos actos de sabotaje que ayuden a paralizar realmente el país" (Álvarez, 2011: 213). La idea del PC era que el FPMR desarrollara acciones armadas que tuviesen efectos políticos. El FPMR se traza como objetivo ser la vanguardia conductora del pueblo chileno en la batalla contra la dictadura, desmarcándose "de toda posibilidad de negociación, privilegiando la vía armada como única salida" (Zalaquett, 2011: 2).

Para la naciente organización militar, el PC recluta a militantes principalmente de su juventud durante los primeros años de la década del '80. Estos militantes fueron capacitados en tácticas militares y técnicas de combate, en el uso de armamento y explosivos, sin embargo, sólo será en diciembre de 1983 cuando el FPMR haga su aparición pública, a través de un organizado apagón que afectó a varias ciudades del país. 


\section{La Población La Pincoya}

En la zona norte de Santiago, en el Conchalí de los años '60, el alto número de allegados, debido a la falta de viviendas, motivó a numerosas familias a organizarse en el Comité de los Sin Casa, quienes tras varias tentativas y no recibir respuestas satisfactorias de las autoridades, decidieron tomarse los terrenos ubicados en el sector de Guanaco, el 26 de Octubre de 1969, dando origen a un campamento que fue bautizado como Pablo Neruda. El diario comunista El Siglo, indica que el nombre fue "propuesto por un viejo poblador en homenaje a la Unidad Popular" (El Siglo, 27-X-1969). El campamento Pablo Neruda recibió una importante influencia de vecinos militantes de partidos de izquierda, lo que favoreció que sus dirigentes políticos intercedieran ante Carabineros para evitar el desalojo. El Mercurio indicó al respecto: "los políticos marxistas fueron de los primeros en llegar a la toma de terreno" (El Mercurio, 27-X-1969). Los mismos parlamentarios colaboraron posteriormente en proponer el traslado del campamento a su actual ubicación en La Pincoya (El Siglo, 31-X-1969).

La población La Pincoya tuvo como base al campamento Pablo Neruda que llegó trasladado desde Guanaco, contando "además de la Villa Wolf, la Patria Nueva, Última Hora y Villa el Rodeo, sectores que también llegaron hacia fines de los '60 y primeros años de los 70" (Molina/Molina, 2013: 54).

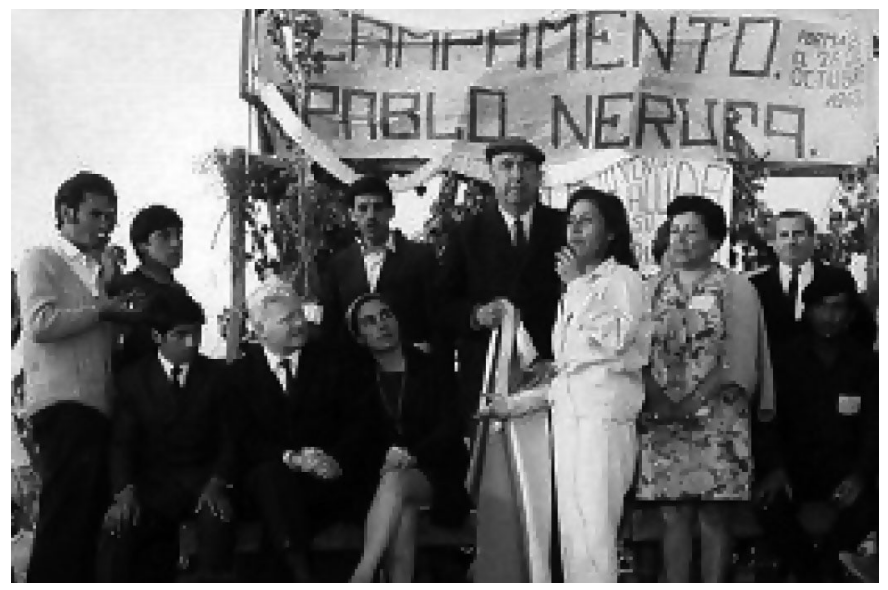

Fotografía publicada por Cecilia Schick y Bernardo Becerra, Soy la Pincoya, Imágenes de Nuestra Historia, Editorial S/I, Chile, 2007: 79.

La población fue fortaleciendo sus vínculos con la izquierda, gracias a la constante presencia de dirigentes comunistas, destacando la visita que realizó el poeta Pablo Neruda, como aparece en la fotografía arriba expuesta. También Salvador Allende estuvo en La Pincoya, lo que, para Raúl Madariaga, creó una "identificación de la comunidad con el gobierno de la 
Unidad Popular" (2010: 30). Luego del Golpe de Estado, la cercanía con la UP sería utilizada como argumento por parte de las fuerzas armadas contra los habitantes de la población.

\section{El Golpe de Estado y la rearticulación de los pobladores}

El primer allanamiento que sufre la población se materializó el 13 de septiembre de 1973, el cual tuvo como objetivo buscar a dirigentes políticos locales simpatizantes del gobierno de Allende e intimidar a los pobladores para evitar cualquier resistencia a las nuevas autoridades. En el primer allanamiento masivo, los detenidos fueron llevados al sector de las "siete canchas". Para Raúl Madariaga este sector se "transformó en un verdadero campo de concentración en La Pincoya" (2010: 50-51). Muchos de los detenidos en el allanamiento nunca más volvieron a sus hogares, engrosando el listado de los detenidos desaparecidos.

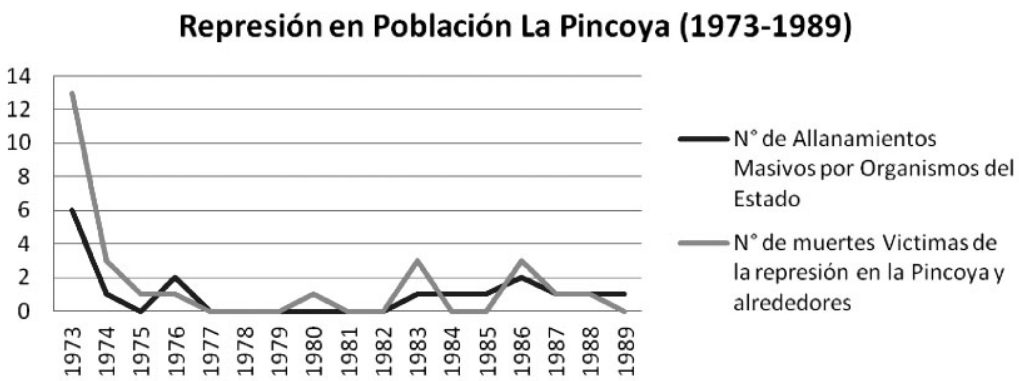

Fuente: Elaboración propia en base a Informe Verdad y Reconciliación, conocido como Informe Rettig, y Torturas en Poblaciones del Gran Santiago (1973-1990), elaborado por la Corporación José Domingo Cañas, Chile, 2005.

Será durante los primeros años del Golpe donde se concentra la represión en la población y el mayor número de vecinos asesinados por organismos del Estado, como lo graficamos en el cuadro arriba expuesto.

\section{Rearticulación Política y Social}

Si bien el Golpe impactó a los pobladores, la rearticulación política y social en La Pincoya se comenzó a dar el mismo 11 de septiembre. Un grupo de militantes del Partido Comunista y de su juventud se organizan, de acuerdo al relato del poblador Lucio Pulgarés, para "esperar armas que vendrían desde el regimiento y permitirían resistir el golpe" (Entrevista personal, 1-VIII-2014). El dirigente comunista Jorge Valdés coincide afirmando: "la gente el mismo momento empezó a organizarse, pero no había nada, solo cahuines, chismes 
de que venía, que iba a llegar (armas), pero no había, porque nunca hubo" (Entrevista personal, 2-VIII-2014).

Abortada la idea de resistir el Golpe, tocó la tarea de resguardarse y comenzar lentamente a contactar a los que estuvieran en condiciones de militar en la clandestinidad. Jorge Valdés indica que le "tocó comenzar a contactar compañeros para rearticular al partido, visitándolos y conversando con ellos para ver si estaban dispuestos a estar en la resistencia, estar ahí" (Entrevista personal, 2-VIII-2014).

Si bien la escuálida organización inicial no permitía una oposición significativa desde la población, sí permitió atender necesidades urgentes de los vecinos, como el hambre fruto de la cesantía de exonerados y el cierre de muchos empleos generados por el depuesto gobierno. Lucio Pulgarés indica: "luego del Golpe vino el hambre, muchos trabajos fueron cerrados, muchas personas fueron exoneradas y no tenían qué comer sus hijos, el hambre fue muy grande" (Entrevista personal, 1-VIII-2014). El ex frentista de la población, Toño, al respecto indica: "entre el 74 y el 78 fue lo más duro, el hambre se palpaba en la calle y el miedo, estaba esa conjunción de hambre y miedo que se palpaba" (Entrevista personal, 13-VII-2011).

El miedo y la desconfianza entre los vecinos también se vivió en la población; Jorge Valdés nos confidencia que "la gente tenía mucho miedo, no se daban la cara ni para mirar, había mucho temor" (Entrevista personal, 2-VIII-2014). Ese temor inicial fue muy difícil de revertirlo, sin embargo, los encuentros en torno a las ollas comunes y posteriormente de los centros culturales apoyados por la Iglesia Católica, sirvieron como lugar de encuentro entre los vecinos. La Iglesia conjuntamente crea grupos de salud, los que a juicio de Mario Garcés "no solo contribuyeron a resolver algunos problemas apremiantes de la sobrevivencia, sino que además eran un espacio de encuentro y de participación para muchos vecinos del sector" (Garcés, 1997: 123).

Con el paso de los años, estas primeras organizaciones se vieron ayudadas por la solidaridad internacional, a través de diversas ONG, como también por el apoyo que se brindó desde la Vicaría de la Solidaridad ${ }^{5}$, creciendo y diversificándose estas instancias de pobladores.

Al iniciarse la década del '80, el movimiento de pobladores fue perdiendo el temor, comenzando a visualizarse en el imaginario la posibilidad de terminar con la dictadura. Los encuentros entre vecinos, las conversaciones en los

Para Charles Harper, la Vicaría se había abocado a la "titánica tarea de brindar asistencia legal y social a los ciudadanos chilenos, recabar datos y elaborar análisis sobre la situación de represión en el país" (Harper, 2007: 68). 
centros culturales, algunos rayados en las calles y la música los estimulaba a imaginar un Chile sin dictadura. Lucio Pulgar al respecto nos indica: "en ese periodo queríamos derrocar a la dictadura, volver al camino que habíamos perdido, establecer una sociedad socialista" (Entrevista personal, 1-VIII-2014). Pero las protestas no comenzarán hasta que la crisis económica impacte con la cesantía a los pobladores, creciendo la frustración y la hostilidad al régimen en el sector, especialmente de los más jóvenes. El ex frentista Toño nos relata: "Nos íbamos enterando de la muerte de uno, de otro, la represión que se veía en la calle, eso en lo más político y en lo cotidiano el hambre que había, desesperanza, era un caminar en el desierto, y ahí uno decía jhay que hacer algo!, porque aquí nos vamos a cagar de infelices, veíamos los discursos cuando decían que íbamos a ser un país próspero y llegabas a tu casa y no había ni un pan para comer" (Entrevista personal, 13-VII-2011). Por esto "las protestas poblacionales combinaron sentimientos de frustración e irritabilidad, en especial del segmento juvenil y de desempleados, los más golpeados con la política neoliberal del régimen" (Salazar, 1999: 126).

Las movilizaciones sociales toman fuerza y diversifican sus formas: desde las protestas callejeras con la instalación de barricadas y enfrentamientos con Carabineros, pasando por marchas pacíficas, cacerolazos, lanzamiento de panfletos y pintadas callejeras. Los jóvenes toman protagonismo en este contexto, comenzando a rearticular los lazos de solidaridad y compromisos perdidos tras el golpe, dejando atrás el miedo que imperó un largo tiempo en el sector. Para José Weinstein los jóvenes militantes de partidos mostraron una mayor organización en su lucha contra la dictadura, ya que poseen además una idea más clara de la sociedad que les gustaría vivir, "su compromiso con la causa les da determinados símbolos de identidad, determinadas ideasfuerza y determinados líderes que les son propios. Tienen un nivel superior de información al resto de la población en lo que concierne al desarrollo de la protesta, y planifican acciones concretas para llevar a cabo durante esta jornada. En síntesis, tienen propuestas claras con respecto a la expresión de la protesta" (1988: 57).

En este ambiente, muchos jóvenes pincoyanos comienzan a configurar un imaginario revolucionario, en el anhelo de terminar con la dictadura derrocando a Pinochet, usando incluso la vía armada. Manuel Antonio Garretón indica que los sectores populares "buscan sobre todo la dimensión expresiva, lo que va a converger con la radicalización política de algunos sectores de oposición que se inclinan a posiciones de corte insurreccional y militarizada" (1987: 125)

Este fenómeno de radicalización de la lucha en La Pincoya se puede entender, a juicio de Katty Schneider, porque "el movimiento de protesta surgió con más fuerza en los mismos barrios "rojos" que habían sido el centro de la actividad política de izquierda años antes del golpe militar. En estas pobla- 
ciones, una relación orgánica entre militantes políticos y pobladores permitió que las comunidades se organizaran durante un periodo de represión intensa y, en el contexto de la crisis política de 1982, se movilizaran a gran escala" (Schneider, 1990: 223). Este proceso de radicalización en las protestas por parte de los jóvenes pobladores confluyó con la política de rebelión popular llevada adelante por el Partido Comunista, propiciando en estos jóvenes el desarrollo de un imaginario revolucionario.

Este nuevo imaginario que se comienza a gestar en sectores juveniles, llevó a muchos militantes de izquierda, en especial de las Juventudes Comunistas (JJCC), al convencimiento de que era la lucha armada la forma de enfrentar a la dictadura. De este modo, varios militantes de la "Jota", bajo el alero del partido, comienzan a unirse a las nacientes Unidades de Combate (UC) que el PC comenzó a crear. Las UC de la Jota son utilizadas según el ex frentista Toño, "en cosas menores, como en barricadas con fuego y en la fabricación y utilización de bombas molotov" (Entrevista personal, 13-VII-2014). Paralelamente, el PC creó una instancia intermedia entre el FPMR y las JJCC, estas fueron las Milicias Rodriguistas, siendo "una organización apropiada para la lucha callejera a la que daban lugar las protestas" (Yocelevzky, 2002: 249), quedando el FPMR para aquellos que tuviesen un compromiso mayor en la lucha directa por derrocar a la dictadura.

\section{Construcción del imaginario revolucionario y el FPMR en La Pincoya}

Con la puesta en marcha de la PRPM por parte de la dirección del PC, varios de sus jóvenes militantes pasan a formar parte del FPMR. Esta acción fue replicada en la zona de estudio, la cual además contaba con elementos propios de su historia e identidad local, junto con la experiencia familiar de muchos jóvenes, lo que contribuyó tanto a la generación del imaginario como al ingreso al Frente.

Entrevistas realizadas a dirigentes del PC en la zona y a ex miembros del Frente nos indican que "las unidades de combate de la población estaban divididas en tres: las pertenecientes a las JJCC, las Milicias Rodriguistas y las del FPMR; con respecto a esta última las unidades de combate fueron cuatro. Un problema con respecto a identificar las unidades de combate, está relacionado con la compartimentación que se desarrolló en términos orgánicos y operativos, lo que implicaba desconocimiento de quienes componían las distintas unidades y de lo que hacían. Esto servía como mecanismo de seguridad para los integrantes del FPMR en ese periodo y constituye hoy una dificultad para la recopilación de información" (Molina / Molina, 2013: 59). 
Los jóvenes que ingresaron al FPMR imbuidos en el imaginario revolucionario, debieron desvincularse de sus antiguas organizaciones, básicamente por razones de seguridad de este grupo armado que operaba en clandestinidad, llegando al punto de renegar de ella. Por esto, Rolando Álvarez plantea que "la militancia en el FPMR creó una forma particular de vivir y entender la participación en política" (Álvarez, 2009: 3). Según relata el ex frentista Toño, "pasar al Frente significaba una responsabilidad re grande (...) era como un premio por ser un cuadro responsable, comprometido, un excelente militante" (Entrevista personal, 13-VII-2011).

La mayoría de las personas que ingresaron al Frente en La Pincoya, provenían de antiguas familias comunistas del sector, como relata el ex frentista Toño: "mi familia tenía militancia comunista, mi mamá fue parte de la gestación de la organización de la toma, porque militaba, ella era funcionaria del partido (...) por esto después del golpe mi mamá junto a mis dos hermanos mayores pasan a la clandestinidad y mi padre es tomado prisionero y llevado a Tejas Verdes" (Entrevista personal, 13-VII-2011). La influencia política familiar fue uno de los factores clave en el ingreso al FPMR, contribuyendo con ello al imaginario revolucionario que desarrollaron estos jóvenes, previo a comprometerse en la lucha armada. De Igual manera, las experiencias traumáticas que vivieron les generó una imagen hostil hacia la dictadura, impulsándolos de igual manera a ingresar al Frente. Otro entrevistado, Michel, nos señala al respecto: "el año 1976 habían fusilado a mi Papá en la Vega Central, lo anduvimos buscando por años (...) pero hasta el día de hoy no lo encuentran (...) eso marcó una hueva hacia el sistema, hacia los milicos, hacia lo que estaba pasando". (Entrevista personal, 11-I-2010).

La Pincoya se conformó de varios asentamientos, como la Villa Golf, Pablo Neruda y Última Hora, siendo la Pablo Neruda -a juicio de Cristóbal Peña- "la más combativa de las tres que formaban La Pincoya" (2007: 23). Este fenómeno se da por la influencia política que tiene dicho lugar desde sus inicios, lo que generó que los frentistas provenientes de la Pablo Neruda fueran numéricamente más que los de otros sectores de La Pincoya y fueran quienes participaran en las más importantes acciones armadas.

Para iniciarse en el Frente, los pincoyanos se capacitan en diversas tácticas y técnicas de combate, utilizando los cerros que rodean la población preferentemente en el adiestramiento militar, así como también en la preparación física que debían tener los frentistas, situación que nos ratifica el ex frentista Toño, quien afirma que "en las siete canchas nos entrenábamos todos los sábados, domingos y miércoles (...) también en los cerros probábamos cuetes [explosivos]" (Entrevista personal, 13-VII-2011)".

Militando en el Frente, las acciones que desarrollaban alimentaban el espíritu revolucionario. Las "periódicas "tareas" que debían cumplir, ya sea 
de inteligencia, sabotaje o acciones de "recuperación", todas ellas increcendo conforme van adquiriendo experiencia y formando el "temple" " (Molina/ Molina, 2013: 59-60), los comprometió íntegramente en la materialización del imaginario.

Esta preparación, le permitió a dos grupos operativos del Frente provenientes de La Pincoya, asaltar la estación de metro Ciudad del Niño, a fines de 1985. "El grupo de La Pincoya tuvo la misión de asaltar la boletería e instalar dos kilos de explosivos en los andenes, previo desalojo del público. Fue una operación de suma complejidad, que requirió la acción de dos grupos operativos a cargo de Sacha y que incluso sorteó la intervención de un carabinero, que fue neutralizado con un balazo en la pierna" (Peña, 2007: 68). El nombre de Sacha es la "chapa" utilizada por Juan Moreno Ávila, frentista pincoyano que tuvo preparación militar en Cuba y que será posteriormente uno de los frentistas a cargo de las unidades operativas en el atentado a Pinochet.

Estas acciones subversivas fueron "templando" a los pincoyanos, para las acciones de mayor importancia de 1986, fecha establecida como "el año decisivo" por la dirección del PC.

"El Partido Comunista asume resueltamente el propósito de terminar con la dictadura en 1986 y compromete todo su empeño en el logro de este objetivo: firmeza revolucionaria y las acciones combativas elevan la moral de las masas, llevan la incertidumbre, el desconcierto y hasta el pánico al campo del enemigo y nos acercan a la derrota de la dictadura y a la consecución de la democracia" (Partido Comunista de Chile, marzo-abril 1986: 20-21).

A partir de este llamado del PC, la dirección del Frente ordena profundizar las tareas que deben emprender los grupos de combatientes, en el desarrollo de la PRPM. Según Toño, "el Frente inició una weá para tomarse el poder, obviamente rompiendo con la dictadura" (Entrevista personal, 13-VII-2011).

Dentro de las acciones que emprenden los pincoyanos durante el llamado año decisivo, fue frecuente el atentar contra torres de alta tensión, buscando alterar el funcionamiento productivo del país. "La idea era hacerle olitas a Pinochet por donde fuera" (Entrevista personal, Jorge Valdés, 2-VIII-2014), para ello los cortes de calles, los enfrentamientos con Carabineros, e incluso el robo de camiones fueron usados frecuentemente como forma de propaganda, generando alegría en los simpatizantes de la lucha armada. "Era una alegría lo que el Frente hacía y no caían" (Entrevista personal, Jorge Valdés, 2-VIII-2014).

Uno de los actos de sabotaje más importantes de un grupo operativo de La Pincoya fue el atentado al Metro de Santiago el 16 de junio de 1986, 
"instalando un explosivo en un vagón del ferrocarril en la estación Tobalaba. La acción tenía como propósito alterar el "orden" que pretendía dar a conocer el régimen, para ello los frentistas idearon un plan, el cual incluía conocer las rutinas de seguridad de la estación, haciéndose pasar por pasajeros" (Molina/ Molina, 2013: 62). Dicha acción no se la adjudicó el FPMR debido a la muerte de un civil, lo que sería condenable para la opinión pública. Al respecto el Subsecretario del Interior Luís Alberto Cardemil indicó a la prensa: "eso fue una acción menos hipócrita y más demostrativa de lo que es el terrorismo y de lo que pretende" (La Tercera, 17-VI-1986).

Conforme pasan las semanas, las acciones no se detendrán, instalando un auto bomba frente al Regimiento Blindado "Libertadores" de Santiago, dejando a un frentista pincoyano muerto. Este deceso, en un contexto de imaginario revolucionario, era para los frentistas "como un costo asociado a la lucha que estábamos dando" (Entrevista personal, Toño, 13-VII-2011). La idea del FPMR era atentar en contra del capitán Pedro Fernández Dittus, retenido en dicho regimiento, por ser el militar que estuvo a cargo de la patrulla que quemó a Carmen Gloria Quintana y a Rodrigo Rojas Denegrí, los primeros días de julio de 1986.

El ex frentista Toño, que conocía de la operación, nos comenta: "Yo los vi la noche anterior a la acción misma (...) había un compañero encargado de ejecutar a distancia con un control remoto la explosión, que se iba a tirar desde Matta con Santa Rosa, con una radio, que iba a activar un switch cuando el auto estuviese en la puerta del regimiento (...) el compañero que preparó el auto dijo yo lo coloco porque yo soy el explosivista, pero Pato (John Patricio Malhue) dijo no, yo voy, porque yo soy el chofer, ( ) hubo una pequeña discusión y se decidió que el chofer tenía que ir, porque era su función manejar el auto. Pero no tenía ningún conocimiento de cómo manejar el tema explosivos (...) " (Entrevista personal, 13-VII-2011).

"Cuando el Pato va a poner el auto al frente del regimiento, se estaciona el auto y lo echan los milicos [...] el Pato solo saca el cable a la fuente de poder, no al detonador mismo [...] Pato da la vuelta en el auto por Emiliano Figueroa, para dejarlo a un costado el auto [del regimiento] cuando él vuelve a poner el cable a la fuente de poder se activa la carga y [estalla el auto] (...) "nadie alcanzó a activar nada, es un error del manejo de la hueá con los nervios..." (Entrevista personal, Toño, 13-VII-2011).

Con la muerte del frentista John Patricio Malhue la policía realiza un allanamiento a su vivienda en el pasaje El Pueblo, sin saber la familia -hasta

6 Por el carácter de las lesiones, resultó muerto Rodrigo Rojas De Negri, sobreviviendo Carmen Gloria Quintana a pesar de sus graves quemaduras. 
ese momento- de la suerte de John. "La revisión realizada por efectivos policiales de civil no encontró armas ni antecedentes que ligaran al difunto con grupos subversivos, indicaría la prensa (La Tercera, 5-VIII-1986), sin embargo el allanamiento obligaría al resto de los frentistas de la población a movilizarse y tomar resguardos.

Al respecto el ex frentista pincoyano Michael indica "si uno moría no importaba, mientras aportara a la causa de algo servía". El investigador Eduardo Valenzuela indagó sobre esta ética sacrificial de jóvenes en los años ochenta, indicando que "para estos jóvenes la vida cotidiana es un espacio de aburrimiento, miseria y soledad. La lucha (e incluso la muerte) en cambio dignifican, liberan y reconcilian consigo mismo y con la sociedad (1984: 56), por ello muchos jóvenes comprometidos con la lucha armada, asumían como un costo asociado la posibilidad de perder la vida.

El punto más alto en acciones armadas, fue la participación en el atentado a Pinochet en el Cajón del Maipo, en septiembre de 1986. En esta operación participaron veintiún miembros del FPMR, actuando cuatro pincoyanos como "fusileros", y destacando Sacha como encargado de uno de los grupos. Otros tres oriundos de la población estuvieron en el apoyo logístico de la fuga post atentado. La investigadora Patricia Verdugo (1996), en su libro Operación Siglo $X X$, explica que los frentistas que participaron en el atentado, se prepararon en un sector de La Pincoya conocido como las siete canchas?. La investigación desarrollada por CIPER indica que "Juan Soto Pastrian, alias Marcos, formó parte del Grupo de Asalto $\mathrm{N}^{\circ} 2$ o Unidad 503. Actuó desde la ladera de un cerro y tuvo a cargo un lanzacohetes LAW. De hecho, fue su arma la que impactó la ventana del Mercedes Benz ocupado por Pinochet, sin que alcanzara a explotar"8. Junto a Soto Pastrian otros pincoyanos participaron: Lenin Fidel Peralta Véliz, quien usaba de chapa el nombre Oscar; Jorge Mario Angulo González, alias Pedro y Juan Moreno Ávila, mencionado anteriormente como Sacha. Los cuatro operaron como fusileros de acuerdo a la investigación de Cristóbal Peña (2007) dando cuenta del nivel de preparación militar que tenían los frentistas pincoyanos.

Una vez perpetrado el atentado y sobreviviendo Pinochet, los organismos de seguridad del Estado comienzan una ardua tarea destinada a encontrar a los frentistas culpables, dando certeros golpes a la organización de izquierda y demostrando el nivel de conocimiento de ella. Toño, en ese

Ver Patricia Verdugo, Carmen Hertz, Operación Siglo XX, Ediciones Chile América CESOC, $17^{\circ}$ edición, Chile, 1996.

8 Ver: http://ciperchile.cl/2010/12/06/la-cinematografica-historia-del-mas-escurridizoguerrillero-del-fpmr/ 
contexto, indica: "después del atentado no se podía entrar a La Pincoya, estaba prácticamente tomada por la fuerza represiva" (Entrevista personal, 13-VII-2011). Dentro de las represalias post atentado, se ejecutó la denominada Operación Albania, donde mueren doce rodriguistas en un falso enfrentamiento, sobreviviendo Cecilia Valdés Toro, hija de una emblemática familia comunista de La Pincoya. Jorge Valdés, padre de Cecilia, recordando el proceso nos comenta: "me dio temor con la Operación Albania, porque yo sabía que ellos estaban metidos (sus hijos); afortunadamente ella salvó, porque si la agarraba la CNI a ella la mataban con hijo y todo" (Entrevista personal, 2-VIII-2014).

Cecilia Valdés pudo posteriormente entregar su testimonio a la justicia, permitiendo con ello demostrar la responsabilidad de miembros de la CNI en la operación y permitiendo su encarcelamiento.

\section{El fin de la lucha armada}

Tras el fallido atentado y el decomiso de armas interceptadas en Carrizal, el PC se vio aislado políticamente y obligado a cambiar su estrategia, debiendo tender puentes con otras fuerzas políticas y sociales que buscaban recuperar la democracia. Este cambio lo hace a los pocos días de desarrollada la acción armada en el camino al Cajón del Maipo.

"El Partido Comunista llama a los trabajadores y a todas las fuerzas democráticas a no dejarse intimidar, a desarrollar aun más la lucha por la democracia y la libertad, a llevar adelante la concertación social y a formular una sola propuesta política para el tránsito de la dictadura a la democracia. La victoria será del pueblo" (Partido Comunista de Chile, 1986).

Este cambio de estrategia implicó aceptar la Vía Institucional, sumándose posteriormente a la campaña del No para derrotar electoralmente a Pinochet, dejando atrás la política insurreccional que había encabezado.

En este nuevo escenario, el FPMR vive una profunda crisis interna con respecto a qué camino seguir, quebrándose internamente en dos facciones: El FPMR Partido, que sería desmovilizado y el FPMR Autónomo, que continuaría la lucha armada. Rolando Álvarez indica que la escisión de una parte del Frente con el PC, se debió también a "diferencias en la identidad y cultura política propia del llamado "rodriguismo" (...) estallada la crisis, esta identidad y cultura política propia los hizo sentirse más de esa experiencia que la propiamente comunista (Álvarez, 2009: 2). Contrario a la tesis de Álvarez, el grueso de los frentistas pincoyanos que venían de una tradición familiar comunista, los llevó a seguir la línea del partido. Al respecto Toño nos indica: "yo recuerdo haber tenido una discusión con un 
compañero, él me dice "somos rodriguistas!!", a lo que yo le respondo: "yo no soy rodriguista, soy comunista, ser rodriguista es una eventualidad en la vida no más! y yo acato lo que diga el partido". Cuando dicen que hay que inscribirse yo acato y entiendo que habíamos sido derrotados, que el Frente y la lucha armada había sido en una etapa determinada (Entrevista personal, 13-VII-2011). De acuerdo a nuestra investigación, si bien hubo frentistas pincoyanos que se alejaron de la nueva línea política del PC, la mayoría continuó -a pesar de sus múltiples reparos- la línea política familiar y del partido.

\section{Conclusiones}

En el proceso de recuperación de la democracia, las poblaciones del Gran Santiago jugaron un importante papel a la hora de manifestarse abiertamente en contra de la dictadura. La Pincoya se inscribe en ese proceso; apelando a su historia e identidad, fue manifestando desde el primer día distintas y escalonadas formas de oposición, llegando a la lucha armada, con la generación de Unidades de Combate del FPMR.

La crisis económica, y sus consecuentes altos niveles de cesantía, incitó a los pobladores pincoyanos a perder el miedo y expresarse abiertamente contra el régimen, adquiriendo gran protagonismo los jóvenes, quienes participan activamente de las distintas jornadas de protesta. Estos jóvenes desarrollaron un imaginario revolucionario que tenía como patrón común un Chile sin dictadura, mostrando a través de una dimensión expresiva su oposición violenta al régimen, la cual confluyó con la política de rebelión de masas que el Movimiento Democrático Popular. encabezado por el Partido Comunista, llevaba adelante.

El FPMR se nutrió de jóvenes de la población, los cuales saliendo de la anomia, fueron construyendo un imaginario revolucionario que los motivó a ingresar a esta organización militar de izquierda, con la convicción de terminar con la dictadura a través del levantamiento popular que les permitiría "volver al camino que habíamos perdido, establecer una sociedad socialista" (Lucio Pulgarés, entrevista personal, 1-VIII-2014).

Los frentistas alimentaron su imaginario desde la memoria e identidad histórica de su población, junto a las experiencias personales y familiares que marcaron su posición contraria al régimen, radicalizando sus posturas y desafiando a la autoridad del periodo, asumieron una ética sacrificial que los llevó a desarrollar osadas e incluso violentas acciones armadas relevantes para la historia del Chile contemporáneo. 


\section{Referencias bibliográficas}

\section{Fuentes primarias}

\section{a. Entrevistas}

Ex Miembro del FPMR, Toño, 13-VII-2011.

Ex Miembro del FPMR, Michel, 11-I-2010.

Poblador Lucio Pulgarés, 1-VIII-2014.

Dirigente comunista de la Población Jorge Valdés, 2-VIII-2014.

\section{b. Prensa}

EL SIGLO, "El pueblo conquista su vivienda", Santiago, 29 de octubre de 1969.

EL SIGLO, "Verdaderas soluciones piden en campamento Pablo Neruda", Santiago, 31 de octubre de 1969.

EL MERCURIO, "900 personas tomaron terrenos en Conchalí", Santiago, 27 de octubre de 1969.

LA TERCERA, "Atentados al Metro muestran qué es y qué pretende el terrorismo", Santiago, 17 de junio de 1986.

LA TERCERA, "Criminal Atentado en el Metro", Santiago, 17 de julio de 1986.

LA TERCERA, "Auto Cargado de Explosivos voló en pedazos frente a Regimiento", Santiago, 5 de agosto de 1986.

\section{Fotografías}

SCHICK, C. y B. BECERRA (2007). Soy la Pincoya, Imágenes de Nuestra Historia. Chile: Editorial S/l.

\section{Fuentes secundarias}

\section{a. Libros y artículos}

ÁLVAREZ, R. (2009). "Los hermanos Rodriguistas". La división del Frente Patriótico Manuel Rodríguez y el nacimiento de una nueva cultura política en la izquierda chilena. 1975-1987", en Izquierdas, año 2, Número 3, Chile. 
ÁlVAREZ, R. (2011). Arriba los pobres del mundo: cultura e identidad política del Partido Comunista de Chile entre democracia y dictadura. 1965-1990. Santiago: LOM ediciones.

ANGELL, A. (2005). Elecciones Presidenciales, Democracia y Partidos Politicos en el Chile Post Pinochet. Santiago: Instituto de Historia, PUC, y Centro de Estudios Bicentenario.

BOBBIO, N. (1984). Diccionario de Política. México: Siglo XXI.

CASTORIADIS, C. (1994). Los dominios del hombre. Las encrucijadas del laberinto. Argentina: Gedisa.

CASTORIADIS, C. (2007). La institución imaginaria de la sociedad. Argentina: Tusquets.

CORVALÁN MARQUÉZ, L. (2001). Del anti capitalismo al neoliberalismo en Chile. Chile: Editorial Sudamericana.

GALLARDO, H. (1997-1998). "Revolución", en Boletín de Filosofía, N9, Vol.2. Santiago: Universidad Católica Blas Cañas.

GARCÉS, M. (1997). Historia de la comuna de Huechuraba. Memoria y oralidad popular urbana. Chile: ECO Educación y Comunicación.

GARRETÓN, M. A. (1987). "La complejidad de la transición invisible. Movilizaciones populares y régimen militar en Chile", en Proposiciones, $N^{\circ} 14$. Chile: Ediciones SUR.

HARPER, CH. (2007). El acompañamiento. Acción ecuménica por los Derechos Humanos en América Latina. Uruguay: Ediciones Trilce.

MADARIAGA, R. (2010). Historia de la Población La Pincoya. 1969-1989, a través del Relato de sus pobladores, Chile: Taller de memoria histórica-Comité Arte y Cultura La Pincoya.

MARTíNEZ, L. (S/i). "Lo militar y el FPMR en la política de rebelión popular de masas: origen y desarrollo", en Alternativa, № 23. Chile: ICAL.

MOLINA JARA, J. y N. Molina Vera (2013). "Expresiones de la lucha contra la dictadura: La Población La Pincoya y el Frente Patriótico Manuel Rodríguez", en Divergencia, №3, Año 2, enero-julio 2013.

MOULIAN, T. (1997). Chile actual: Anatomía de un mito. Santiago: LOM ediciones.

PARTIDO COMUNISTA DE CHILE (1986). Boletín del Exterior. Hagamos de 1986 el año de la victoria (manifiesto del Partido Comunista al Pueblo de Chile), No 77, marzo-abril.

PARTIDO COMUNISTA DE CHILE (1986). Boletín del Exterior, No dejarse intimidar, Declaración del Partido Comunista, № 81, noviembre-diciembre. 
PEÑA, C. (2008). Los Fusileros, crónica de una guerrilla en Chile. Chile: Editorial Debate.

SALAZAR, G. y J. Pinto (1999). Historia Contemporánea de Chile II. Actores, Identidad y Movimiento. Santiago: LOM Ediciones.

SCHNEIDER, C. (1990). "La movilización de las bases, poblaciones marginales y resistencia en Chile autoritario", en Proposiciones, No 19. Chile: Ediciones SUR.

SUBERCASEAUX, B. (2009). "Imaginario político de transformación", en Universum, año 24, vol. 2. Chile: Universidad de Talca.

VALDIVIA, V. (2010). "¡Estamos en Guerra, Señores!". El régimen militar de Pinochet y el "pueblo", 1973-1980", en Historia, № 43, Vol. I. Santiago: Instituto de Historia, Pontificia Universidad Católica de Chile.

VALENZUELA, E. (1984). "La Rebelión de los jóvenes", en Proposiciones, Tomo $\mathrm{XI}$, Año V. Chile: Ediciones SUR.

VERDUGO, P. y C. HERTZ (1996). Operación siglo XX. Chile: Ediciones Chile América CESOC, $17^{\circ}$ edición.

WEINSTEIN, J. (1988). Los Jóvenes pobladores en las protestas nacionales (19831984). Una visión sociopolítica. Chile: CIDE.

YOCELEVZKY, R. (2002). Chile: Partidos políticos, democracia y dictadura 19701990. Chile: Fondo de Cultura Económica.

ZALAQUETT, C. (2011). "La frentista Fabiola": Un relato "en reversa" del atentado a Pinochet", en Izquierdas, № 9, abril.

\section{b. Páginas web}

"La cinematográfica historia del más escurridizo guerrillero del FPMR", en http:// ciperchile.cl/2010/12/06/la-cinematografica-historia-del-mas-escurridizoguerrillero-del-fpmr (visitado el 22 de abril de 2014) 